\title{
Ultrasensitive paper-based photoelectrochemical sensing platform enabled by the polar charge carriers-created electric field
}

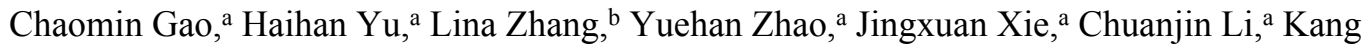

$$
\text { Cui, }{ }^{* a} \text { and Jinghua } \mathrm{Yu}^{* a}
$$

${ }^{a}$ School of Chemistry and Chemical Engineering, University of Jinan, Jinan, Shandong 250022, PR. China.

${ }^{b}$ Shandong Provincial Key Laboratory of Preparation and Measurement of Building Materials, University of Jinan, Jinan 250022, PR China.

*Corresponding author: Jinghua Yu

E-mail: ujn.yujh@gmail.com

Telephone: $+86-531-82767161$ 


\section{Table of Contents}

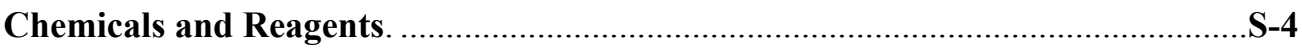

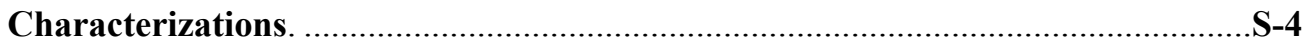

Design and preparation of the paper-based sensing platform. ............................S-5

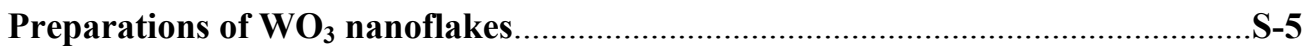

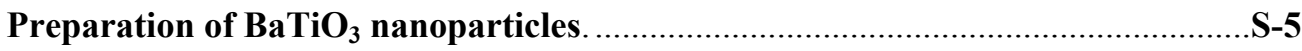

Preparations of $\mathrm{WO}_{3}$ nanoflakes/BTO

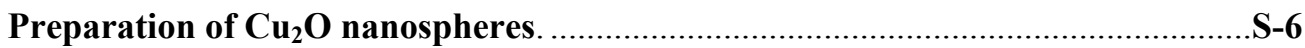

Preparations of $\mathrm{WO}_{3}$ nanoflakes $/ \mathrm{BTO} / \mathrm{Cu}_{2} \mathrm{O}$ photoelectrode.................................6-6

The investigation of the influence of polarization treatment on the stability of photoelectrode

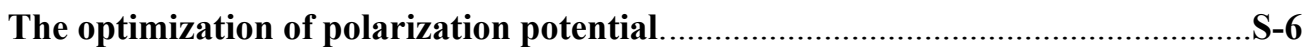

Construction and assay procedures of the sensing platform ....................................

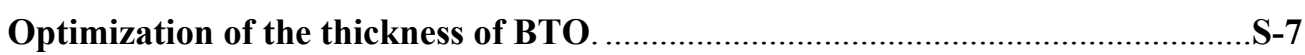

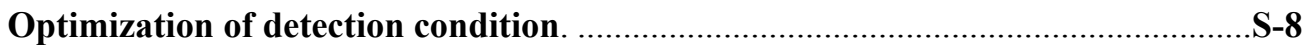

Shceme S1. The construction and assay procedures of the sensing platform................S-9

Figure S1. The illustration of the as-designed paper-based sensing platform.............S-10

Figure S2. (a) Photocurrent response of the polarized $\mathrm{WO}_{3}$ nanoflakes/BTO/Cu $2 \mathrm{O}$ after stored for over four weeks. (b) The influence of the polarization potential on the photocurrent response of $\mathrm{WO}_{3}$ nanoflakes $/ \mathrm{BTO} / \mathrm{Cu}_{2} \mathrm{O}$.

Figure S3. SEM mapping of $\mathrm{WO}_{3}$ nanoflakes/BTO/Cu $2 \mathrm{O}$ sample

Figure S4. The full range XPS spectrum of $\mathrm{WO}_{3}$ nanoflakes $/ \mathrm{BTO} / \mathrm{Cu}_{2} \mathrm{O}$ sample......S-13

Figure S5. High-resolution XPS spectra of O 1s.

Figure S6. $\mathrm{PL}$ spectra of $\mathrm{WO}_{3}$ (curve a), $\mathrm{WO}_{3}$ nanoflakes $/ \mathrm{Cu}_{2} \mathrm{O}$ (curve b), and $\mathrm{WO}_{3}$ nanoflakes/BTO/ $\mathrm{Cu}_{2} \mathrm{O}$ after poling (curve c).

Figure S7. Effect of thickness of BTO on the photocurrent response.

Figure S8. Effect of incubation time of antigen with antibody (a), $\mathrm{pH}$ value (b), and concentration of AA (c) on photocurrent responses of sensing platform with the PSA concentration of $1 \mathrm{ng} / \mathrm{mL}$ in PBS buffer (0.01 mol/L, $\mathrm{pH}$ 7.4). 
Figure S9. The photocurrent responses of the paper-based sensing platform after stored for over four weeks with the PSA concentration of $0.15 \mathrm{ng} / \mathrm{mL}$. .S-18

Table S1. Decay parameters and average lifetime according to a bi-exponential fitting model of the PL decay curves obtained from the samples. .S-19

Table S2. Comparison of different methods for the detection of PSA. .S-19

Table S3. Determination of PSA in human serum samples. S-19 
Chemicals and Reagents. Sodium stannate, urea, ascorbic acid (AA, $\geq 99.0 \%$ ), and bovine serum albumin (BSA) were obtained from Sigma-Aldrich Chemical Co. PSA and antibody of PSA were obtained from Shanghai Linc-Bio Science Co. LTD (Shanghai, China). diethylene glycol (DEG), barium hydroxide $\left(\mathrm{Ba}(\mathrm{OH})_{2} \cdot 8 \mathrm{H}_{2} \mathrm{O}\right)$, sodium hydroxide $(\mathrm{NaOH})$, ethanol $\left(\mathrm{CH}_{3} \mathrm{CH}_{2} \mathrm{OH}\right)$, isopropanol, lactic acid, tetrabutylammonium hydroxide solution, hydrochloric acid $(\mathrm{HCl}), \mathrm{CuSO}_{4}$, sodium dodecyl sulfate, 1-ethyl-3-(3-(dimethylamino) propyl) carbodiimide hydrochloride (EDC), N-hydroxysuccinimide (NHS), and hydroxylamine hydrochloride were purchased from Aladdin (Shanghai, China). The commercialized Ag slurry which with high oxidation resistance was purchased from Shanghai Julong Electronic Technology Co., Ltd. Whatman chromatography paper no. 2 (pure cellulose paper) was obtained from GE Healthcare Worldwide (Pudong Shanghai, China). All reagents were used as received with analytical grade. Ultrapure water was used in all experiments obtained from a Lichun water purification system (Jinan, China) $(>18.25$ $\mathrm{M} \Omega \mathrm{cm})$.

Characterizations. The morphologies of samples were characterized using a QUANTA FEG 250 thermal field emission scanning electron microscopy (FEI Co., USA). The photocurrent response was measured with a $\mathrm{CHI} 660 \mathrm{C}$ electrochemical working station (Shanghai Chenhua Instrument Co., China). Steady-state photoluminescence (PL) and time-resolved PL measurements were acquired using an FLS980 fluorescence spectrometer (Edinburgh Instruments) under a laser excitation of $310 \mathrm{~nm}$. Piezoelectric force microscopy (PFM) measurements were performed at the modulation frequency via a lock-in amplifier (HF2LI, Zurich Instruments, Switzerland). The XPS results were obtained using X-ray photoelectron spectroscopy (ESCA210, VG) with A1 Ka X-ray generator (1486.6 eV). 
Design and preparation of the paper-based sensing platform. At first, Adobe Illustrator CS6 was used to design the shape patterns of the paper-based sensing platform (Figure S1). The paper substrate was cut into the independent device for $\mathrm{WO}_{3}$ nanoflakes growth. Then, the wax was selected to obtain the hydrophobic barrier (the bright yellow and blue color zones) in the way of hand-drawn. Finally, after the preparation of $\mathrm{WO}_{3}$ nanoflakes/BTO/Cu $2 \mathrm{O}$, carbon counter and $\mathrm{Ag} / \mathrm{AgCl}$ reference electrodes were obtained with a screen-printed method.

Preparations of $\mathbf{W O}_{3}$ nanoflakes. Firstly, a layer of commercialized Ag slurry which with high oxidation resistance was deposited on the paper work zone with the screen-printed method to endow the satisfactory conductivity. Then, a $0.231 \mathrm{~g}$ of sodium tungsten dehydrate $\left(\mathrm{Na}_{2} \mathrm{WO}_{4} \cdot 2 \mathrm{H}_{2} \mathrm{O}\right)$ as the tungsten source was dissolved in $30 \mathrm{~mL}$ of deionized water with stirring at room temperature, followed by addition of $10 \mathrm{~mL}$ of $3.0 \mathrm{M} \mathrm{HCl}$ and $0.2 \mathrm{~g}$ of ammonium oxalate $\left(\left(\mathrm{NH}_{4}\right)_{2} \mathrm{C}_{2} \mathrm{O}_{4}\right)$. After several minutes of stirring, $30 \mathrm{~mL}$ of ultrapure water was added under continuous stirring for $30 \mathrm{~min}$. The as-prepared precursor was transferred into a $100 \mathrm{~mL}$ of Teflon-lined stainless autoclave. The paper substrate with the conducting side facing down was immersed and leaned against the wall of the Teflon vessel. The hydrothermal synthesis was carried out at $140{ }^{\circ} \mathrm{C}$ for $2 \mathrm{~h}$.

Preparation of $\mathrm{BaTiO}_{3}$ nanoparticles. Briefly, $20 \mathrm{~g}$ of $\mathrm{NaOH} / \mathrm{KOH}$ (52:49) was mixed thoroughly and put into a $50 \mathrm{~mL}$ Teflon-lined autoclave. Then, $0.13 \mathrm{~g} \mathrm{BaCl}_{2}$ and $0.04 \mathrm{~g}$ anatase $\mathrm{TiO}_{2}$ was added into the mixture. Finally, the autoclave was sealed and heated at $200{ }^{\circ} \mathrm{C}$ for $40 \mathrm{~h}$. After that, the obtained sample was dissolved, filtered, and washed thoroughly with ultrapure water and $0.05 \mathrm{M} \mathrm{HCl}$ to remove the excessive hydroxide.

Preparations of $\mathbf{W O}_{3}$ nanoflakes/BTO. The as-obtained $\mathrm{BaTiO}_{3}$ was modified onto the $\mathrm{WO}_{3}$ nanoflakes based on vacuum vapor phase deposition strategy. $100 \mathrm{mg}$ of $\mathrm{BaTiO}_{3}$ powders were put into a quadrate $\mathrm{Al}_{2} \mathrm{O}_{3}$ boat serving as the source material, followed by placed into the vacuum chamber. Then the paper-based $\mathrm{WO}_{3}$ nanoflakes stuck onto the sample stage was fixed onto $20 \mathrm{~cm}$ above the boat using the scotch tape. A turbomolecular pump was used to evacuate the vacuum chamber to about 
$8 \times 10^{-6}$ mbar. The evaporation electric current was set to around 30 A. During this process, the temperature of boat rise gradually and the $\mathrm{BaTiO}_{3}$ powders were thermally heated and sublimed onto the paper-based $\mathrm{WO}_{3}$ nanoflakes. The deposition rate was controlled about $0.1 \AA / \mathrm{s}$ which monitored by a quartz microbalance sensor. The deposition amount of $\mathrm{BaTiO}_{3}$ detected by the film thickness meter can be controlled by the evaporation time. The obtained paper-based $\mathrm{WO}_{3}$ nanoflakes $/ \mathrm{BaTiO}_{3}$ was washed thoroughly with ultrapure water.

Preparation of $\mathrm{Cu}_{2} \mathrm{O}$ nanospheres. In a typical synthesis, $0.07 \mathrm{~g} \mathrm{CuCl}{ }_{2} \cdot 2 \mathrm{H}_{2} \mathrm{O}$ was dissolved in $10 \mathrm{~mL}$ ultrapure water, and $0.4 \mathrm{~g}$ PVP was added into the mixture under stirring. Then, $3.6 \mathrm{~mL}$ of $0.4 \mathrm{M} \mathrm{NaOH}$ was dropwise added with continual stirring for 5 min. After that, $4.0 \mathrm{~mL}$ of $0.2 \mathrm{M} \mathrm{L}$-ascorbic acid was added dropwise and the solution was further stirred for another $5 \mathrm{~min}$. Finally, the obtained yellow precipitates were washed with ultrapure water and ethanol for several times to remove the PVP surfactants.

Preparations of $\mathrm{WO}_{3}$ nanoflakes/BTO/ $\mathrm{Cu}_{2} \mathrm{O}$ photoelectrode. The $\mathrm{Cu}_{2} \mathrm{O}$ was modified onto $\mathrm{WO}_{3}$ nanoflakes/BTO with the spin-coating method. $0.1 \mathrm{~g}$ of as-prepared $\mathrm{Cu}_{2} \mathrm{O}$ powder was dispersed into ethanol under stirring. The spin-coating rate was set up as $1000 \mathrm{rpm}$ and the time was about $60 \mathrm{~s}$. The thickness of a $\mathrm{Cu}_{2} \mathrm{O}$ can be controlled by repeating the cycle of spin-coating procedure.

The investigation of the influence of polarization treatment on the stability of photoelectrode. The influence of polarization treatment on the stability of photoelectrode was previously investigated. As shown in Figure S2a, no obviously changes in photocurrent responses are observed for the photoelectrode stored for over four weeks, demonstrating that the polarization treatment has no adverse effect on the stability of photoelectrode.

The optimization of polarization potential. According to the thickness of the BTO and our previous experience, a small polarization potential is required. As shown in Figure $\mathrm{S} 2 \mathrm{~B}$, when the polarization potential is from 0 to $3.0 \mathrm{~V}$, the photocurrent intensity increases as the increase of polarization potential and reaches a constant state at $3.0 \mathrm{~V}$, implying that $3.0 \mathrm{~V}$ is sufficient for the charges rearrangement in the BTO to 
form the PCC electric field. Thus, the $3.0 \mathrm{~V}$ was selected.

Construction and assay procedures of the sensing platform. Briefly, the construction and assay procedures of the sensing platform were shown in Scheme S1. At first, the $\mathrm{WO}_{3}$ nanoflakes/BTO/Cu $2 \mathrm{O}$ photoelectrode was prepared and polarized. The chitosan and glutaraldehyde were used to active the photoelectrode. Briefly, 25 $\mu \mathrm{L}$ of chitosan solution $(0.1 \mathrm{wt} \%)$ was added onto the surface of photoelectrode and being washed with $\mathrm{NaOH}$ solution and ultrapure water when dried. Then, $30 \mu \mathrm{L}$ of glutaraldehyde solution $(5.0 \mathrm{wt} \%)$ was dropped on the photoelectrode and kept for 60 min. After that, the PSA antibody solution $(30 \mu \mathrm{L})$ was dropped onto the activated photoelectrode and incubated at $4{ }^{\circ} \mathrm{C}$ for $6 \mathrm{~h}$, followed by washing thoroughly with ultrapure water. The PSA antibody was immobilized onto the photoelectrode through the classic EDC coupling reaction between carbonyl groups on the surface of the $\mathrm{Cu}_{2} \mathrm{O}$ introducing by the PVP and the amino groups of the PSA antibody. Then, 50 $\mu \mathrm{L}$ of $25 \%$ bovine serum albumin was used to block non-specific binding sites at $4{ }^{\circ} \mathrm{C}$ for $2 \mathrm{~h}$. Finally, the PSA antigen solution $(20 \mu \mathrm{L})$ with various concentrations was added and incubated for $35 \mathrm{~min}$, followed by washing. The photocurrent signals were recorded on a CHI 660C electrochemical working station (Shanghai Chenhua Instrument Co., China) in 0.01 M PSB solution ( $\mathrm{pH} 7.4$ ) with 0.1 M AA. A PLS-SXE 300 xenon lamp $\left(100 \mathrm{~mW} \mathrm{~cm}^{-2}\right)$ with the light wavelength $>420 \mathrm{~nm}$ was used as the irradiation source and the light was switched on and off every $20 \mathrm{~s}$ with the $0 \mathrm{~V}$ applied potential.

Optimization of the thickness of BTO. The thickness of BTO affected the photocurrent response and its thickness was controlled through the evaporation time. As shown in Figure S7, when the evaporation time was no more than $500 \mathrm{~s}$, the photocurrent intensity of the photoelectrode was increasing with the increasing evaporation time. Nevertheless, when the evaporation time is further increasing, the photocurrent response was decreased, which maybe ascribe to that the thick semiconductor BTO layer were not conducive to the charge transporting. Therefore, the optimal evaporation time was set to $500 \mathrm{~s}$. 
Optimization of detection condition. In addition, the incubation time of the antibody and antigen was also optimized with the PSA concentration of $1.0 \mathrm{ng} / \mathrm{mL}$, as shown in Figure S8a. When the incubation time was from 0 to $30 \mathrm{~min}$, the photocurrent intensity decreased as the increase of incubation time and reached a constant state after $35 \mathrm{~min}$. Thus, the $35 \mathrm{~min}$ incubation time was selected. The effect of $\mathrm{pH}$ on photocurrent intensity was shown in Figure S8b. The photocurrent response is increasing with increasing $\mathrm{pH}$ value and reached the maximum value at $\mathrm{pH}$ 7.4. Therefore, pH 7.4 was the optimal value and used in further study. Finally, the effect of the concentration of AA to the photocurrent response was also optimized. As shown in Figure S8c, When the concentration of AA was no more than $0.1 \mathrm{M}$, the current intensity increased gradually with increasing AA concentration; however, when the concentration of AA was further elevated, the photocurrent would decrease. This may be attributed to a much higher concentration of AA would result in the increase of the absorbance of AA in solution, as a consequence, the intensity of the irradiation arriving at the electrode surface decreased and the efficiency of excited light absorbers would decrease. Therefore, $0.1 \mathrm{M}$ was selected as the optimal concentration. 


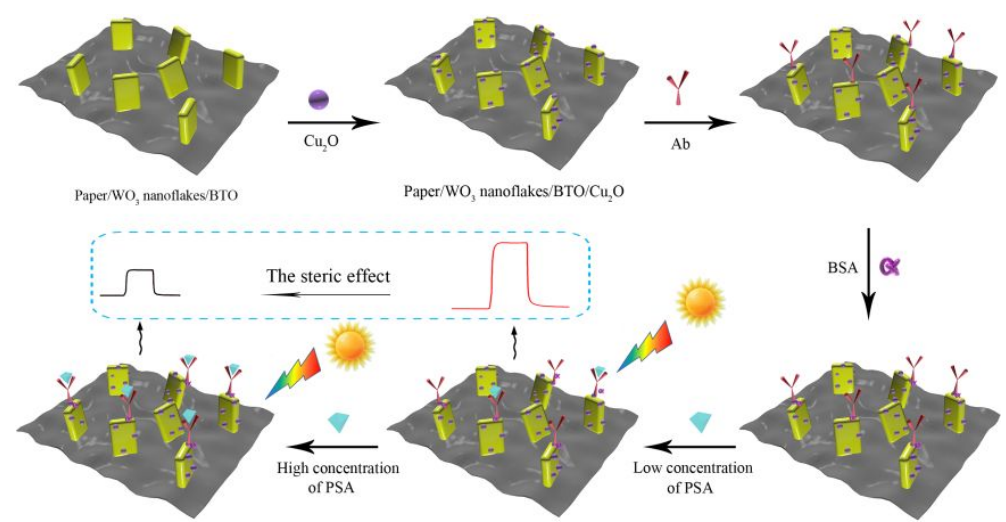

Scheme S1. The construction and assay procedures of the paper-based sensing platform. 


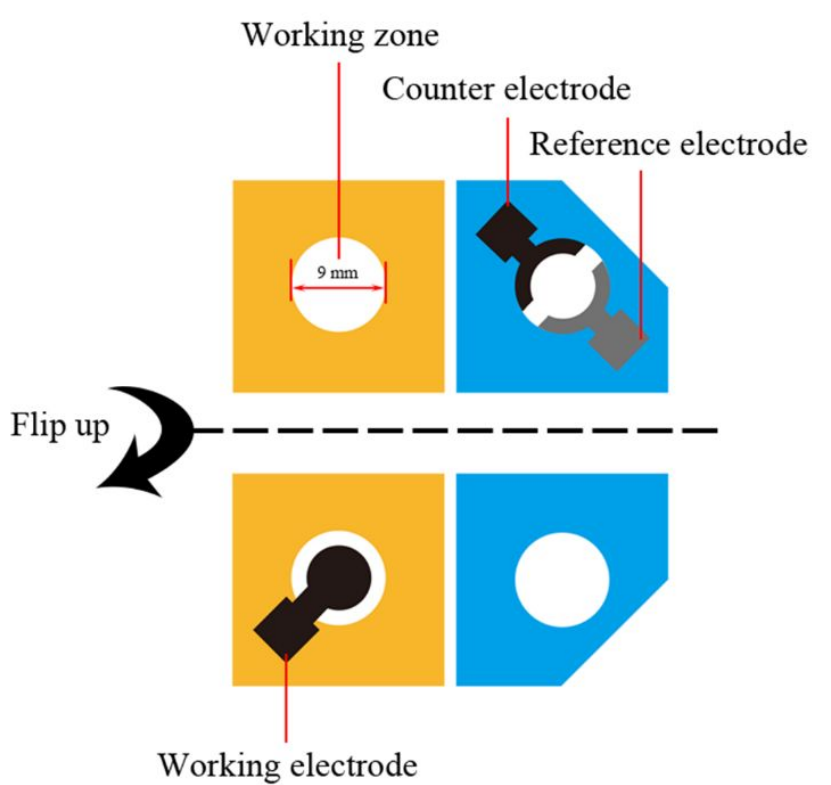

Figure S1. The illustration of the as-designed paper-based sensing platform. 

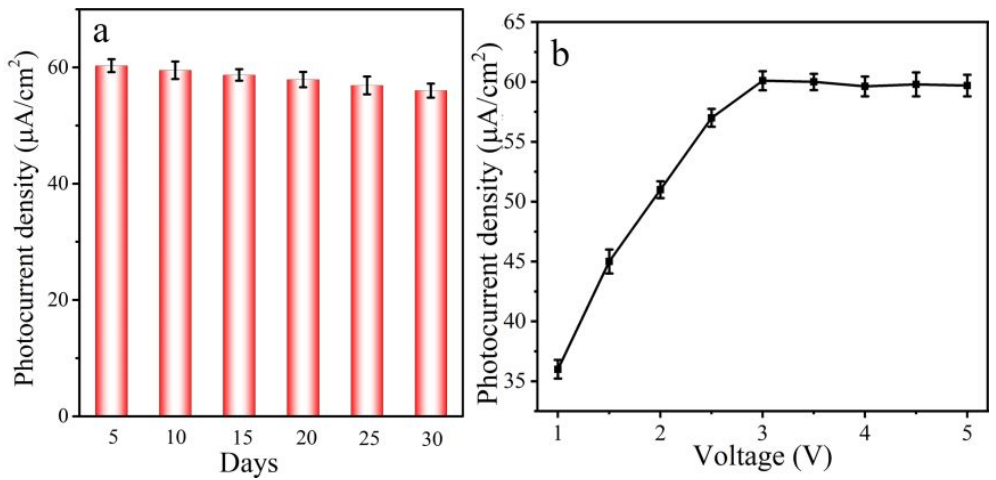

Figure S2. (a) Photocurrent response of the polarized $\mathrm{WO}_{3}$ nanoflakes $/ \mathrm{BTO} / \mathrm{Cu}_{2} \mathrm{O}$ after stored for over four weeks. (b) The influence of the polarization potential on the photocurrent response of $\mathrm{WO}_{3}$ nanoflakes/BTO/ $\mathrm{Cu}_{2} \mathrm{O}$. 


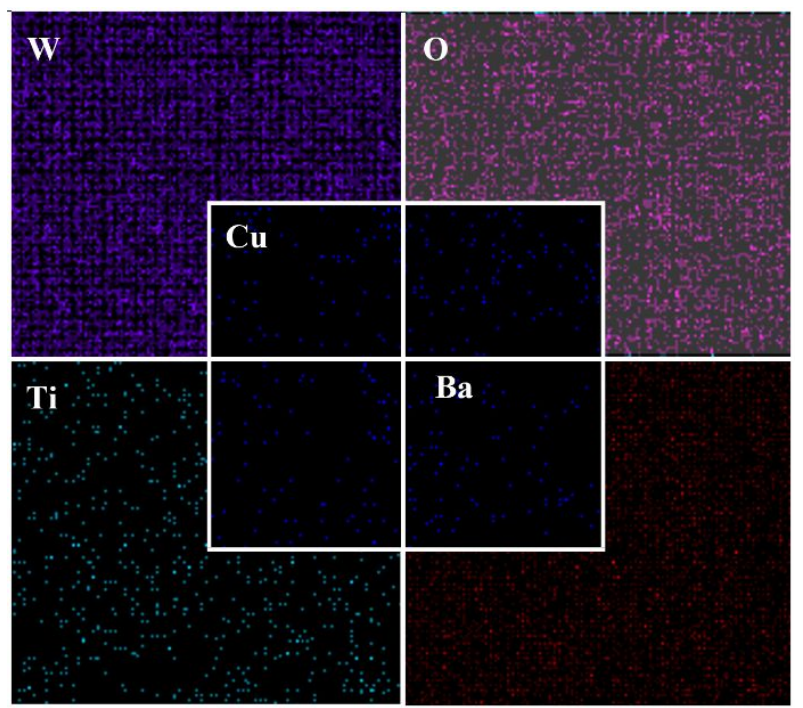

Figure S3. SEM mapping of $\mathrm{WO}_{3}$ nanoflakes $/ \mathrm{BTO} / \mathrm{Cu}_{2} \mathrm{O}$ sample. 


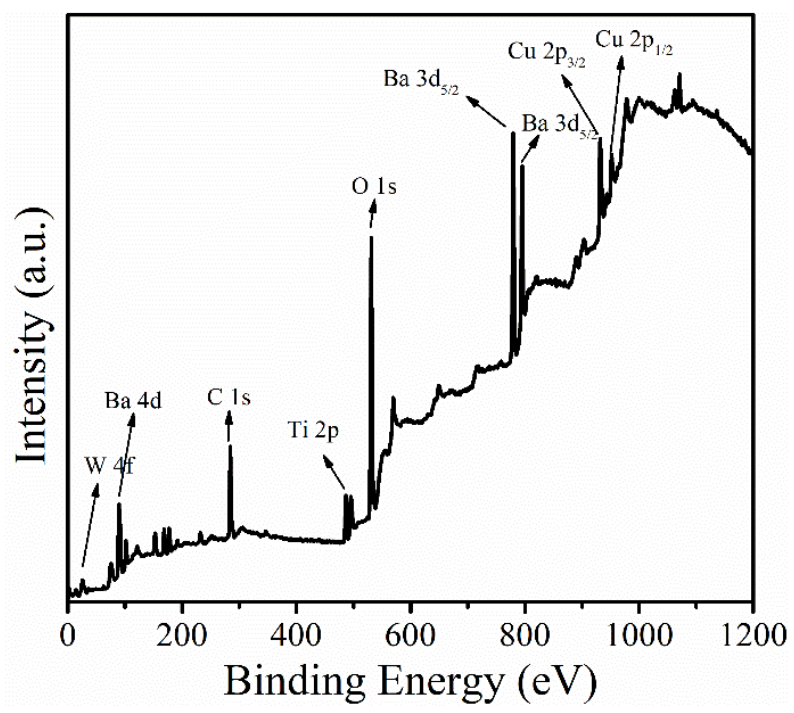

Figure S4. The full range XPS spectrum of $\mathrm{WO}_{3}$ nanoflakes $/ \mathrm{BTO} / \mathrm{Cu}_{2} \mathrm{O}$ sample. 


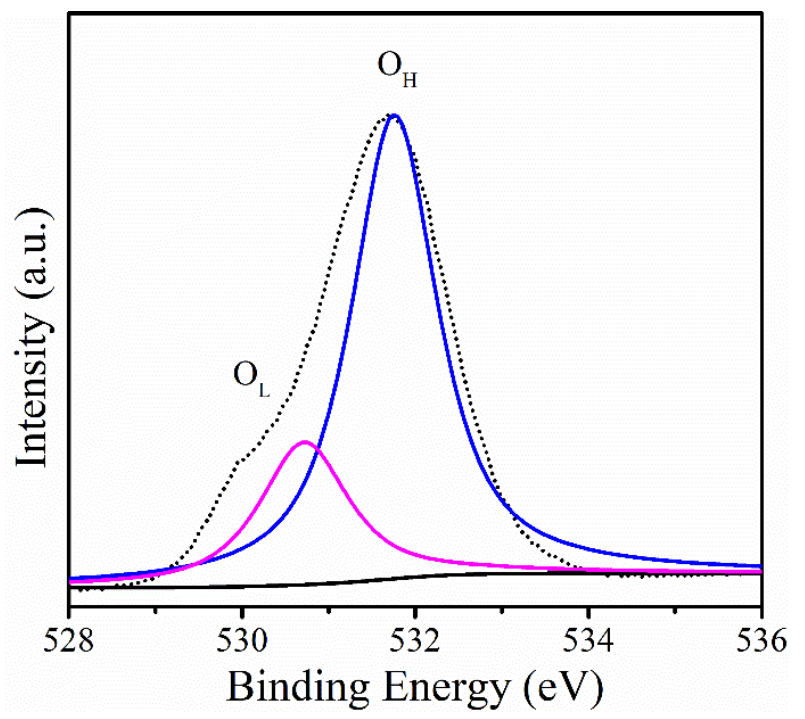

Figure S5. High-resolution XPS spectra of O 1s. 


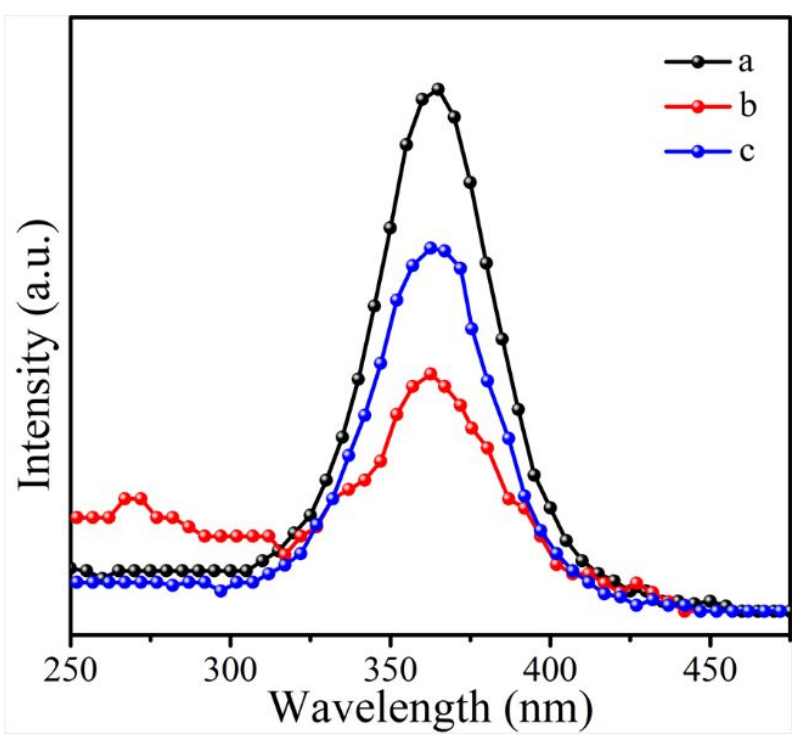

Figure S6. $\mathrm{PL}$ spectra of $\mathrm{WO}_{3}$ (curve a), $\mathrm{WO}_{3}$ nanoflakes $/ \mathrm{Cu}_{2} \mathrm{O}$ (curve b), and $\mathrm{WO}_{3}$ nanoflakes/BTO/ $\mathrm{Cu}_{2} \mathrm{O}$ after poling (curve c). 


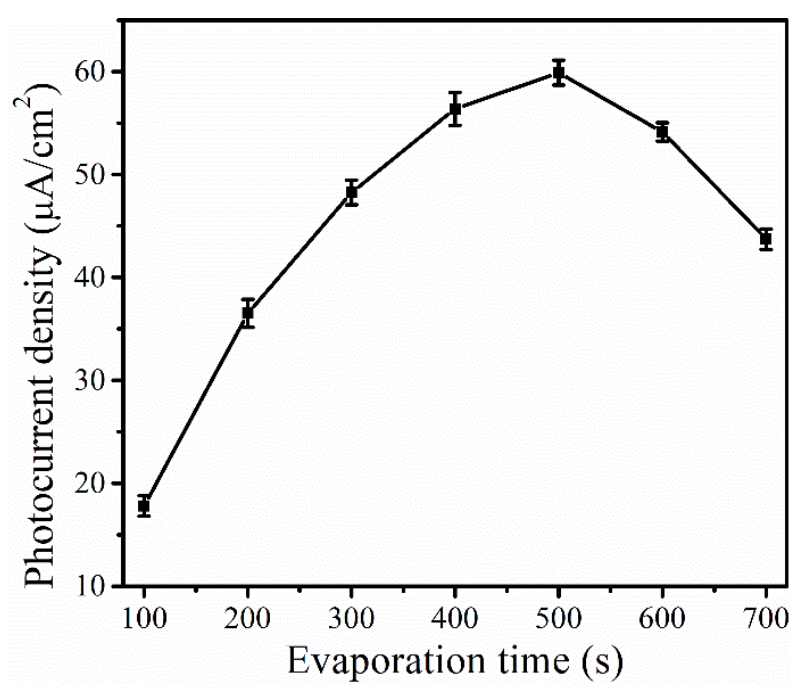

Figure S7. Effect of thickness of BTO on the photocurrent response. 

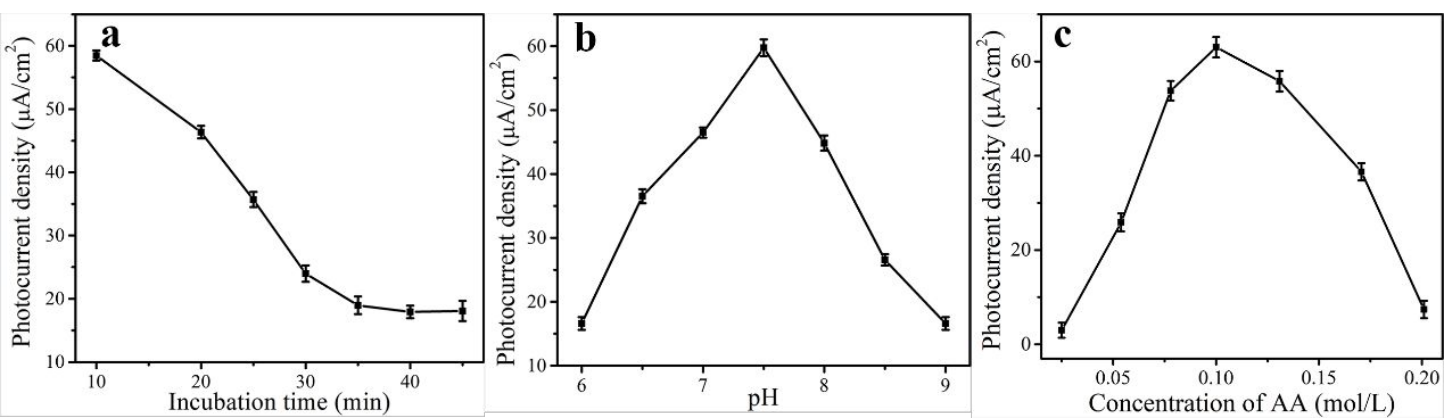

Figure S8. Effect of incubation time of antigen with antibody (a), $\mathrm{pH}$ value (b), and concentration of AA (c) on photocurrent responses of sensing platform with the PSA concentration of $1 \mathrm{ng} / \mathrm{mL}$ in PBS buffer (0.01 mol/L, pH 7.4). 


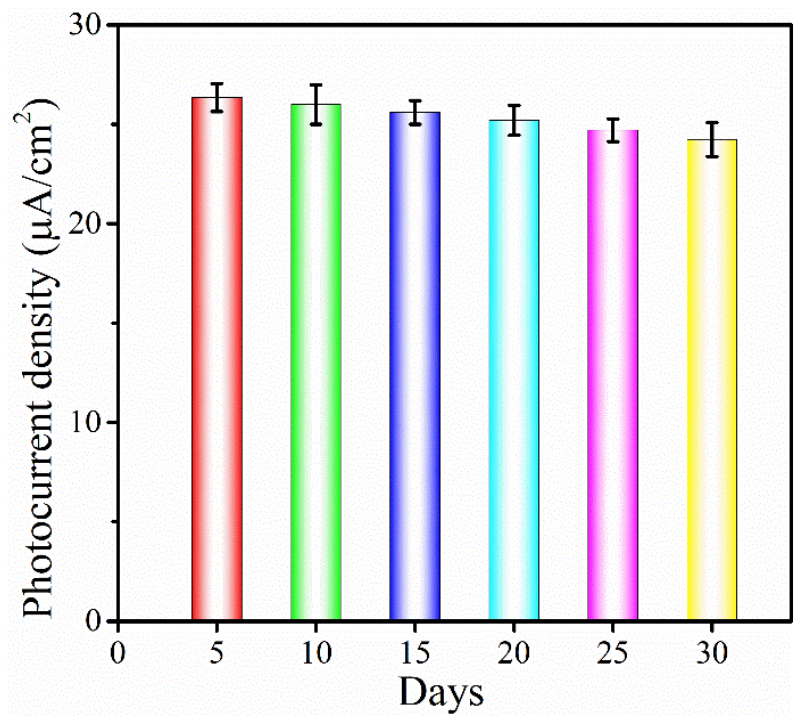

Figure S9. The photocurrent responses of the paper-based sensing platform after stored for over four weeks with the PSA concentration of $0.15 \mathrm{ng} / \mathrm{mL}$. 
Table S1. Decay parameters and average lifetime according to a bi-exponential fitting model of the PL decay curves obtained from the samples.

\begin{tabular}{cccccccc}
\hline Samples & $\tau_{1}(\mathrm{~ns})$ & $\tau_{2}(\mathrm{~ns})$ & $\tau_{3}(\mathrm{~ns})$ & $\mathrm{A}_{1}$ & $\mathrm{~A}_{2}$ & $\mathrm{~A}_{3}$ & $\tau_{\text {ave }}(\mathrm{ns})$ \\
\hline $\mathrm{WO}_{3}$ & 6.95 & 2.45 & 11.34 & 0.08 & 0.61 & 1.55 & 6.90 \\
$\mathrm{WO}_{3}$ nanoflakes $/ \mathrm{Cu}_{2} \mathrm{O}$ & 0.25 & 1.59 & 10.7 & 5.79 & 0.51 & 0.1 & 3.95 \\
$\mathrm{WO}_{3}$ nanoflakes/BTO $/ \mathrm{Cu}_{2} \mathrm{O}$ poling & 1.65 & 0.18 & 13.74 & 0.47 & 38.97 & 0.12 & 2.68 \\
\hline
\end{tabular}

Table S2. Comparison of different methods for the detection of PSA.

\begin{tabular}{cccc}
\hline Methods & Linear range & Detection limit & References \\
\hline Differential pulse voltammetry & $2 \mathrm{ng} / \mathrm{mL}-80 \mathrm{ng} / \mathrm{mL}$ & $1 \mathrm{pg} / \mathrm{mL}$ & 2 \\
Electrochemiluminescence & $1 \mathrm{pg} / \mathrm{mL}-10 \mathrm{ng} / \mathrm{mL}$ & $0.72 \mathrm{pg} / \mathrm{mL}$ & 3 \\
Immunochromatography & $0.5 \mathrm{pg} / \mathrm{mL}-200 \mathrm{pg} / \mathrm{mL}$ & $2.05 \mathrm{pg} / \mathrm{mL}$ & 5 \\
Biofuel cell & $0.3 \mathrm{pg} / \mathrm{mL}-7 \mathrm{ng} / \mathrm{mL}$ & $0.1 \mathrm{pg} / \mathrm{mL}$ & 6 \\
PEC & $1 \mathrm{pg} / \mathrm{mL}-30 \mathrm{ng} / \mathrm{mL}$ & $0.78 \mathrm{pg} / \mathrm{mL}$ & This work \\
\hline
\end{tabular}

Table S3. Determination of PSA in human serum samples.

\begin{tabular}{cccc}
\hline Number & Content of PSA $(\mathrm{ng} / \mathrm{mL})$ & Decovery $(\%)$ \\
\hline 1 & 0.002 & 0.0019 & 95.0 \\
2 & 0.01 & 0.0098 & 98.0 \\
3 & 0.1 & 0.103 & 103.0 \\
4 & 1.0 & & 96.0 \\
5 & 10.0 & 0.96 & 96.6 \\
6 & 5.0 & 4.83 & 105.2 \\
\hline
\end{tabular}


References:

(1) Zhao, M.; Fan, G. C.; Chen, J. J.; Shi, J. J.; Zhu, J. J. Highly sensitive and selective photoelectrochemical biosensor for $\mathrm{Hg}^{2+}$ detection based on dual signal amplification by exciton energy transfer coupled with sensitization effect. Anal. Chem. 2015, 87, 12340-12347.

(2) Kavosi, B.; Salimi, A.; Hallaj, R.; Amani, K. A highly sensitive prostate-specific antigen immunosensor based on gold nanoparticles/PAMAM dendrimer loaded on MWCNTS/chitosan/ionic liquid nanocomposite. Biosens. Bioelectron. 2014, 52, 20-28.

(3) Zhang, N.; Gao, H.; Xu, C. H.; Cheng, Y.; Chen, H. Y.; Xu, J. J. An Efficient Electrochemiluminescence Enhancement Strategy on Bipolar Electrode for Bioanalysis. Anal. Chem. 2019, 91, 12553-12559.

(4) Fang, C. C. C., C. C. Yang, Y. Q. Wei-Kai, T. Wang, Y. T. Chan, Y. H. Multiplexed Detection of Tumor Markers with Multicolor Polymer Dot-Based Immunochromatography Test Strip. Anal. Chem. 2018, 90, 2134-2140.

(5) Gao, C.; Zhang, L.; Wang, Y.; Yu, J.; Song, X. Visible-light driven biofuel cell based on hierarchically branched titanium dioxide nanorods photoanode for tumor marker detection. Biosens. Bioelectron. 2016, 83, 327-333.

(6) Xie, S.; Zhang, J.; Yuan, Y.; Chai, Y.; Yuan, R. An electrochemical peptide cleavage-based biosensor for prostate specific antigen detection via host-guest interaction between ferrocene and beta-cyclodextrin. Chem. Commun. 2015, 51, 3387-3390. 